\title{
Risk Information Sources for Snow Disaster Risk Preparedness in Scotland
}

\author{
Josephine Adekola $^{1,2} \cdot$ Fabrice Renaud $^{2} \cdot$ Carol Hill $^{2}$
}

Accepted: 22 September 2021 / Published online: 15 December 2021

(C) The Author(s) 2021

\begin{abstract}
Heavy snow disruptions are common and costly occurrences in the UK, including Scotland. Yet, heavy snow remains an underresearched aspect of disaster risks in Scotland. This study critically examined the 2018 heavy snow event in Scotland referred to as the "Beast from the East" (BfE) in order to explore the different sources of information used by the public in preparation for and response to heavy snow emergencies. Our study also examined the effectiveness of BfE risk communication between authorities and the public and sought to determine if there is a relationship between risk information received and the intention to mitigate risk. Data were collected through a semistructured survey from $(n=180)$ residents of the Annandale and Eskdale region of Dumfries and Galloway, Scotland. Our analysis shows that public authority information sources were the most sought-after information sources, followed by online and web sources. We found statistically significant differences between groups (such as age, gender, and mobility/disability) in terms of using risk information sources. Further analysis shows that the relationship between information received and the intention to mitigate risks is not linear but influenced by intervening variables such as work pressures, financial commitment, and stakeholders' expectations. We argue that where full adherence to official risk advice is required, policymakers should carefully consider issues around these three factors.
\end{abstract}

Josephine Adekola

Josephine.Adekola@Glasgow.ac.uk

1 Adam Smith Business School, University of Glasgow, Glasgow G12 8QQ, UK

2 School of Interdisciplinary Studies, University of Glasgow, Dumfries DG1 4ZL, UK
Keywords Disaster preparedness $\cdot$ Heavy snow $\cdot$ Risk information sources $\cdot$ Risk perception $\cdot$ Scotland

\section{Introduction}

As communities continue to face risks from environmental hazards such as floods, heavy snow, and extreme heat (Huber and Gulledge 2011), they must make decisions to reduce the threats from these risks, especially in emergencies. In the UK and Scotland, public service authorities such as the Met Office, Scottish Environment Protection Agency (SEPA), and local authorities are responsible for communicating risk messages to the public under the Civil Contingency Act 2004. The act requires these authorities to warn, inform, and advise the public in preparation for and in the event of an emergency. Communicating relevant and timely information alongside preparedness strategies with the public will help citizens develop the appropriate level of risk awareness, which is a fundamental step in disaster preparedness (Steelman et al. 2015; Cahyanto et al. 2016; Bronfman et al. 2019). Research suggests a positive relationship between risk perception and preparedness (Miceli et al. 2008; Cliff et al. 2009; Paul and Bhuiyan 2010). Therefore, the lack of access to timely information, which the public relies upon to make risk judgments, can compromise the ability of individuals and communities to respond effectively to environmental threats. Also, as communities are not homogeneous, it is essential to understand how they differ in their use of risk information sources for risk preparedness.

Existing risk communication research has tended to focus on the perspectives of the information sender, including their perceived view of the receiver's information source preferences to the neglect of actual choices 
from the receiver's perspective (Palttala et al. 2012), although there are exceptions (Burger et al. 2013; Steelman et al. 2015; DeYoung et al. 2016). Burger et al. (2013) examined local communities' use of information sources to prepare for and respond to Super Storm Sandy in New Jersey, United States. Steelman et al. (2015) surveyed 873 local community members in the United States and Mexico to explore recipient perspectives of information used on five large wildfires in 2009 and 2010. DeYoung et al. (2016) studied hurricane evacuation in North Carolina from the perspective of the information recipients. Burger et al. (2013), Steelman et al. (2015), and DeYoung et al. (2016) provide valuable insight into receivers' preferences of information sources in the United States and Mexico. Likewise, research on risk perception has focused on the relationship between risk perception and risk preparedness (Miceli et al. 2008). More scientific attention is still needed to understand recipient perspectives of information used during a snow event and how public groups (by age, gender, and disabilities) differ in their use of risk information sources in the United Kingdom's local context.

This study investigated the public experience of the 2018 heavy snow event in the UK referred to as "Beast from the East" (BfE). The BfE is an interesting case study due to the scale (national) and unusual intensity of the event. The BfE affected most of the United Kingdom with new low temperatures recorded in the sub-zeros and heavy snowfall between 24 February to 4 March 2018 (Greening and Hodgson 2019). The new record low temperatures prompted the Met Office to issue the first-ever red weather warnings in Scotland, thereby stretching local resources. The red warning alert ${ }^{1}$ was in place for several hours on multiple occasions during this event. A red warning means a considerable disruption to travel, critical supplies (energy, water), and property and infrastructure with potential risk to life (Met Office 2018). There were widespread school closures during which roads, offices, shops, and factories across the country were also closed, and with power cuts and minor accidents reported in the news (Guardian 2018). The advice for the public was to avoid any form of travel, where possible, and to follow the official advice provided by emergency services and local authorities. Thus, the BfE in Scotland presents a highly relevant context to study the information sources that different public groups rely upon for risk information in Scotland.

The aim of this study was to examine: (1) what sources of information are used by local communities to access risk information about heavy snow in Scotland; and (2) to understand how public groups differ across age, gender,

\footnotetext{
${ }^{1}$ A full weather warning scale can be found on the MetOffice website: https://www.metoffice.gov.uk/weather/guides/warnings.
}

and mobility/disability in terms of their use of risk information sources during a snow disaster. Understanding the use of information sources in snow disaster preparedness in the UK context is essential for two reasons. First, it provides valuable insight into whether information sources vary depending on the type of hazard. Second, the intensity of a disaster, the nature of its impact (including those affected), and trust in national authorities can shape people's attitude to disaster and how they use and search for risk information. Therefore, this study provides helpful insight into the information-seeking behaviors of people in Scotland and will allow researchers to determine if they differ from those living elsewhere. The article contributes to the disaster risk and community resilience literature by examining risk communication's role from the communication studies perspective. The other two risk communication perspectives are those of the science and technology studies and management perspectives (Adekola et al. 2019).

\section{Risk Communication and Information Sources, Risk Perception, and Intention to Act}

Threats from environmental hazards often prompt a sense of need for risk information to understand better the nature of the hazard. This sense of need is referred to as perceived information insufficiency-a gap between current knowledge and information need (Griffin et al. 2004). This is then followed by information search by those who perceive themselves to be at risk by using multiple media sources to help make sense of the risk (Sommerfeldt 2015). Where there is no direct experience of risk, how the risk is encoded, transmitted, and decoded plays a key role in how the public makes sense of the risk signals. The social amplification of risk framework (SARF) as articulated by Kasperson et al. (1988) and the disaster risk communication literature see the media as a critical information source both before and after a disaster (Holmes et al. 2009; Burger et al. 2013). The SARF, which relies on the structure of communication theory (Shannon and Weaver 1949), illustrates how risk signals are encoded, passed on, received, and interpreted by various sources (Kasperson and Kasperson 2012).

Television, radio, and newspapers are traditional (mainstream) means of communication (Spence et al. 2011; Austin et al. 2012), and play a critical role in informing the public about risk, providing updates, and serving as a watchdog for risk information (Fig. 1). Social media play a role in informing or misinforming the public and are now the first source of publicly provided material (Jin et al. 2014). They have also become sources of information for traditional media and allow the public to be both receivers 


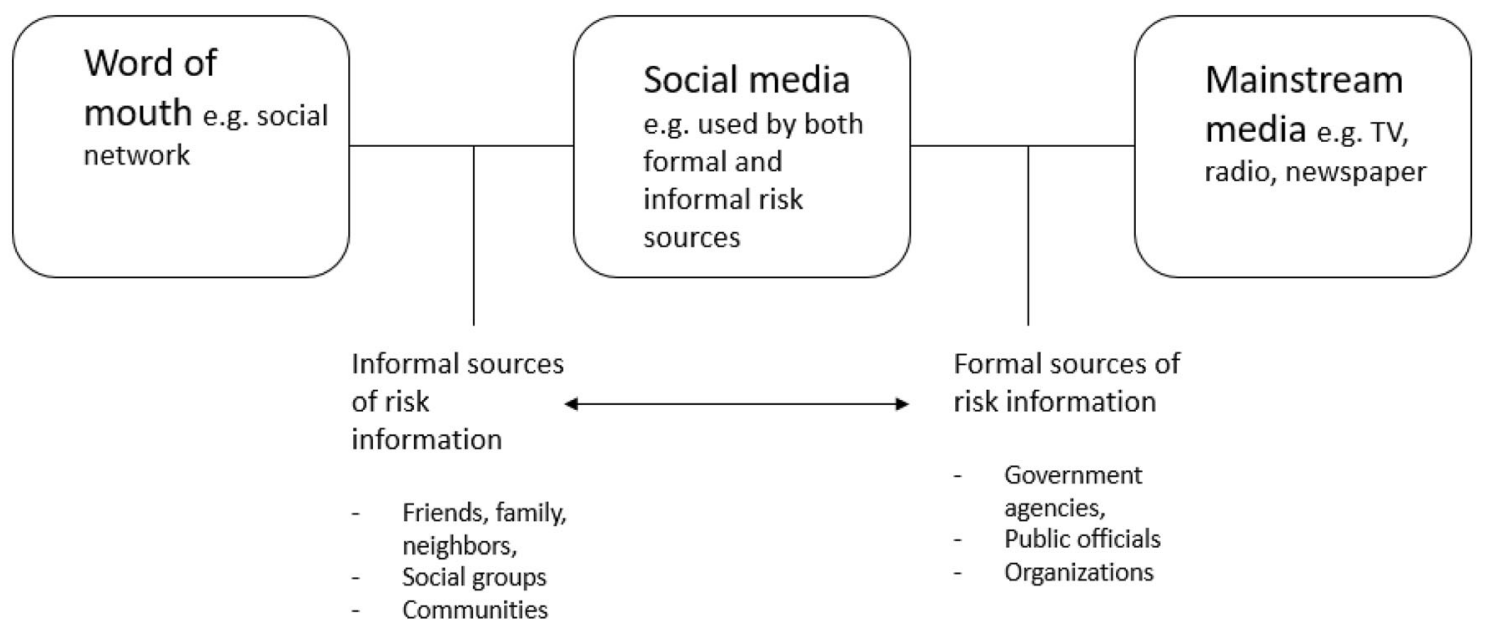

Fig. 1 Communication sources for risk information. Source Adapted from Spence et al. (2011), Austin et al. (2012), and Steelman et al. (2015)

and senders. Online and social media are instrumental in getting localized information, checking on friends and family, and orchestrating relief efforts following a disaster (Austin et al. 2012). Mobile media provide an additional advantage in information sharing and alerts, real-time coverage of risk events, and directing the public away from disaster areas. From this perspective, the information provider may be from official and unofficial sources (Fitzpatrick and Mileti 1994). Family, friends, and neighbors are often highlighted as valuable and trusted information sources (Burnside et al. 2007). Word of mouth is a beneficial source of information that would not necessarily come from authorities (Sutton et al. 2008). Both official and nonofficial sources may use mainstream and social media when communicating with the public. Figure 1 differentiates between formal and informal sources of risk information.

The use of formal and informal information sources has been recognized within the literature. In their study, Burger et al. (2013) found television, radio, friends, and web/email to be the most used sources of information by locals during Superstorm Sandy. In their study of five large fires, Steelman et al. (2015) found that family/friends/neighbors, mass media, and maps were the most used sources of information. DeYoung et al. (2016), in their study of hurricane evacuation in North Carolina, observed that television and radio information sources were the most used sources in that context. DeYoung et al. (2016) identified females and younger residents as the demographic groups that favored multiple sources from which to gather information in contrast to males and older residents. A study by Communicating with Disaster Affected Communities network found that radio was the most used source of information when communicating with communities in the aftermath of Cyclone Idai in Mozambique (CDAC 2019).
Another study by International Organization for Migration shows that the most used sources of information during a flooding event in Pakistan and elsewhere are friends and family, mobile phones, television, and radio (IOM 2014). Other identified sources were through the army, aid workers, newspapers, religious leaders/institutions, community leaders, and government official documents.

Communicating about risk can be challenging because people interpret risk from competing perspectives (objective vs. subjective). People comprehend risk through an informational mechanism, and this can either be through the analytic (scientific) or the experiential system, also known as "risk as analysis" and "risk as feelings" (Slovic et al. 2004). People use a variety of psychological mechanisms to make a judgment about risks. There are "mental short-cuts" called heuristics and risk images (Tversky and Kahneman 1974) that are modified continuously by several variables, including media reports and peer influences. Knowledge, experience, values, attitudes, and emotions also influence judgment about the seriousness and acceptability of risks (Slovic 2010; Madhuri et al. 2015; Hoffmann and Muttarak 2017; Rakib et al. 2017). Furthermore, trust and credibility (Frewer et al. 2003), power and expertise (Adekola 2020), and the phase of a disaster (Ryan 2013,2018 ) play vital parts in shaping how a risk message is received and understood.

The relationship between risk communication, risk perception, and intention to act or take mitigating steps is conceptualized by the social cognitive model (Paton 2005) and protective action decision making framework (Lindell and Perry 2012). The social cognitive model identifies several factors (such as personal, environmental, and social conditions) that enable disaster risk preparedness. For example, the level of motivation combined with self-efficacy acts to shape intentions and preparedness for disaster 
risk (Paton 2005). The protective action decision making framework, on the other hand, argues that the protective action decision-making process (exposure, attention, and interpretation) interacts with situational factors (threat, protective action, and stakeholder perceptions) to produce a behavioral response (Lindell and Perry 2012). In this context, clarity of information, language used, power, expertise, and trust (Adekola 2020) can affect how recipients understand risk information, and take appropriate action to protect themselves or others (Hansson et al. 2020). Similarly, Abunyewah et al. (2019) indicate that accessible, comprehensive, and tailored disaster information strongly influences intentions to prepare for disasters. The social-mediated crisis communication model (Austin et al. 2012) highlights the importance of the social network in facilitating information exchange.

Age, gender, and disability also disproportionally affect capabilities and opportunities to respond effectively to disaster risk reduction (Mayhorn 2005; Cutter 2017; Berget et al. 2020). Age-related perceptual and cognitive changes, such as attention and memory, may also impede understanding disaster-related communication (Mayhorn 2005). Cutter (2017) highlighted how gendered violence exacerbates the impact of disasters, and Berget et al. (2020) suggested that how disabled groups receive risk information is dependent on the type of impairment-cognitive, physical, sensory, or mental health - that may present challenges to comprehension, attention, language, and social skills (Berget et al. 2020)

\section{Methodology}

This study was carried out in the Annandale and Eskdale area, the eastern part of Dumfries and Galloway (Fig. 2). This area was identified as the most impacted area in the region during the BfE by a regional council official. ${ }^{2}$ Annandale and Eskdale cover 156,286 ha, about a quarter of the Dumfries and Galloway region. Its neighbors are Nithsdale, South Lanarkshire, Scottish Borders, and Cumbria. The southern border of the area consists of the Solway Firth coastline. According to the Dumfries and Galloway Health and Social Care Strategic Needs Assessment report (2016-2019), more than half of the population lives in rural or remote areas with over 40,000 people living in the Annandale and Eskdale regional area (Dumfries and Galloway Council Integration Joint Board 2018).

At the time of the BfE event, there were several communication initiatives by both the Scottish Government and

\footnotetext{
$\overline{2}$ Resilience and Community Safety Manager at Dumfries and Galloway Council. Informal face to face discussion on suitable study site.
}

Dumfries and Galloway Council to help individuals and communities prepare for weather-related emergencies. ${ }^{3}$ The Dumfries \& Galloway Virtual Operations Support Team, for instance, is a communication tool used to provide key safety messages and real-time information to the public during emergencies while countering misinformation. It also aids better situational awareness for resilience practitioners by gathering useful data and information from the audience. Through its media outlets (for example, websites, Twitter, and Facebook pages), the Scottish Government provides advice to the public on weather-related emergencies.

This study strictly followed the University of Glasgow ethical committee approval process. Data were collected using a semistructured postal survey between June and July 2018, three months after the BfE disruption in the Dumfries and Galloway region of Scotland. A postal survey enabled the researchers to reach a larger population set as the study location is in a rural and dispersed community setting. We considered an online survey, but determined that this could eliminate an essential segment of the (aging) population.

One thousand postal questionnaires were sent out to residents within postcode areas DG11 and DG10 in the Dumfries and Galloway edited electoral register. There are approximately about 5000 residences within these areas. D\&G has 15 postcode areas, with DG10 and DG11 covering the Moffatt and Lockerbie areas, respectively. Participants were given three weeks to return their responses in a prepaid envelope. One hundred eighty completed surveys were returned, representing $18 \%$ of the 1000 postal surveys sent out. Three of the 1000 envelopes were returned as failed deliveries.

Average wages in $D \& G$ are significantly lower than average wages in Scotland (Crichton Institute 2014). Due to the aging population (at least $22 \%$ of the population are above 65 years old), wages would most likely be just one element of the income equation (Hill and Clelland 2015). About $33 \%$ of the adult population (16 years and above) of the Dumfries and Galloway area have no qualifications. This is higher than Scotland's average of 27\% (Dumfries and Galloway Council 2020).

Table 1 reflects the study respondents' characteristics, and this was compared with existing data in the surveyed, regional, and national areas. Data for the latter were extracted from the 2011 census and the Crichton Institute's Annandale and Eskdale local area profile. The data suggest a similar gender split in Annandale and Eskdale area, Dumfries and Galloway, and Scotland with a slightly higher number of females than males (a difference of around $3 \%$ ) with $2 \%$ more males than females in this study. In terms of the study participants' age characteristics, 18 to

\footnotetext{
${ }^{3}$ See, for example, readyscotland.gov, dumgla.gov.uk, dgvost.uk.
} 


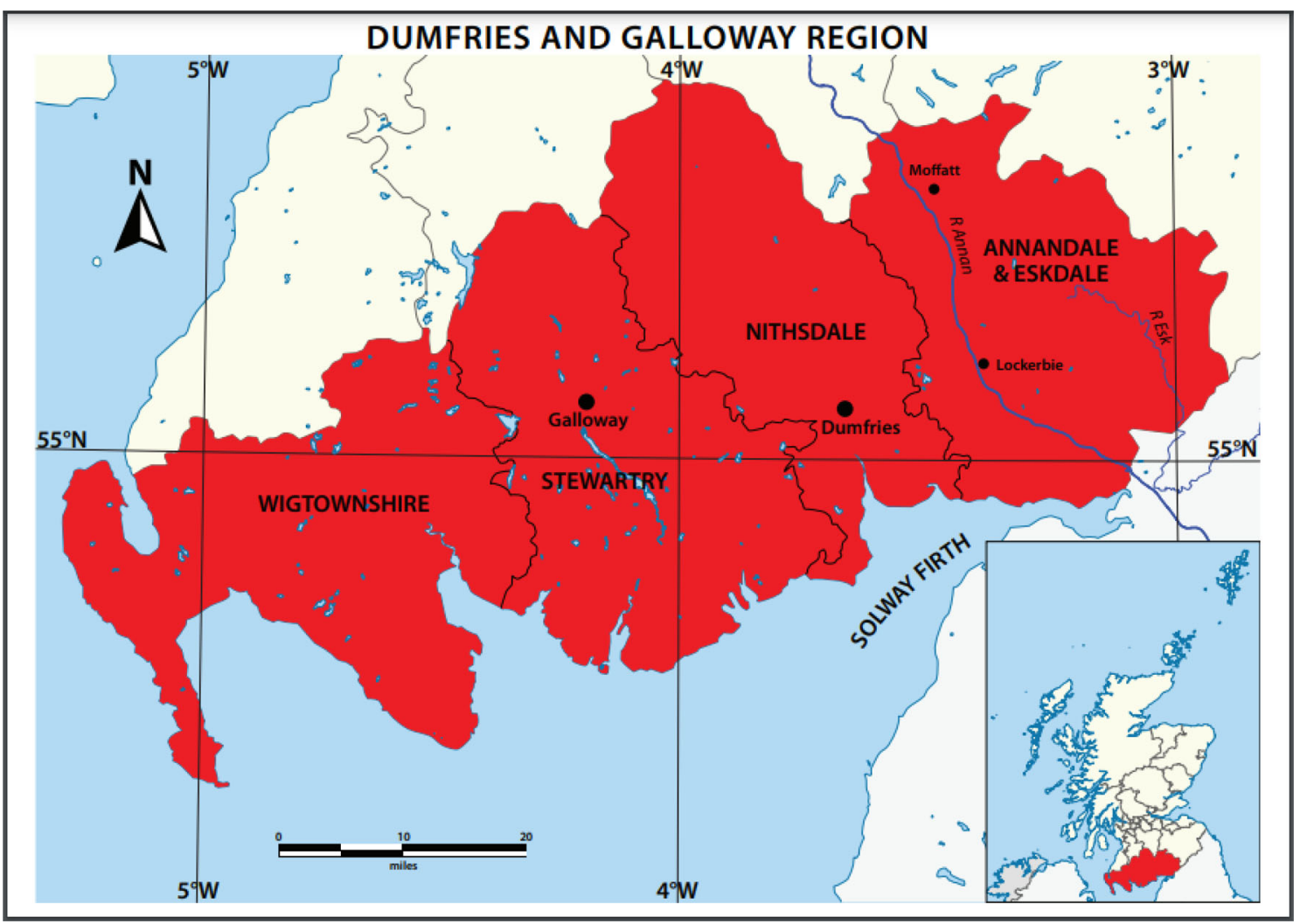

Fig. 2 Map of Dumfries and Galloway in southwestern Scotland

Table 1 Respondents and regional characteristics in Dumbries and Galloway, Annandal and Eskdale, and Scotland

\begin{tabular}{|c|c|c|c|c|c|c|c|c|c|c|c|}
\hline \multirow[t]{2}{*}{ Sample } & \multicolumn{3}{|l|}{ Gender } & \multicolumn{5}{|l|}{ Age } & \multicolumn{3}{|c|}{ A long-term health problem or disability } \\
\hline & Male & Female & $\begin{array}{l}\text { Missing } \\
\text { Info }\end{array}$ & $18-24$ & $25-40$ & $41-60$ & $60+$ & $\begin{array}{l}\text { Missing } \\
\text { Info }\end{array}$ & $\begin{array}{l}\text { Non- } \\
\text { disabled }\end{array}$ & Disabled & $\begin{array}{l}\text { Missing/prefer } \\
\text { not to Say }\end{array}$ \\
\hline Surveyed & $51.7 \%$ & $47.2 \%$ & $1.1 \%$ & $3.3 \%$ & $6.7 \%$ & $33.9 \%$ & $55.6 \%$ & $0.6 \%$ & $75.6 \%$ & 13.9 & $10.5 \%$ \\
\hline Sample & Male & Female & $\begin{array}{l}\text { Missing } \\
\text { Info }\end{array}$ & $0-24$ & $25-44$ & $45-64$ & $65+$ & $\begin{array}{l}\text { Missing } \\
\text { Info }\end{array}$ & $\begin{array}{l}\text { Non- } \\
\text { disabled }\end{array}$ & $\begin{array}{l}\text { Disabled/ } \\
\text { long } \\
\text { term illness }\end{array}$ & $\begin{array}{l}\text { Missing/Prefer } \\
\text { not to Say }\end{array}$ \\
\hline $\begin{array}{l}\text { Annandale } \\
\text { and } \\
\text { Eskdale } \\
\text { Area }\end{array}$ & $48.8 \%$ & $51.2 \%$ & $0 \%$ & $25.9 \%$ & $21.6 \%$ & $30.4 \%$ & $22.1 \%$ & - & $79 \%$ & $21 \%$ & - \\
\hline $\begin{array}{l}\text { Dumfries } \\
\text { and } \\
\text { Galloway }\end{array}$ & $48.5 \%$ & $51.5 \%$ & $0 \%$ & $26.2 \%$ & $21.7 \%$ & $30.2 \%$ & $21.8 \%$ & $0.1 \%$ & $68 \%$ & $22 \%$ & - \\
\hline Scotland & $48.5 \%$ & $51.5 \%$ & $0 \%$ & $29.2 \%$ & $26.4 \%$ & $27.4 \%$ & $16.8 \%$ & $0.2 \%$ & $80.4 \%$ & $19.7 \%$ & - \\
\hline
\end{tabular}

24-year old accounted for $3.3 \%$, and 25 to 40-year old accounted for $6.7 \%$ of those surveyed. 41 to 60 -year old made up $33.9 \%$ and $60+$ years made up $55.6 \%$ of those surveyed. This means an over-representation of the $60+$ years and under-representation of the under 40 years in this study when compared to the official regional data. This discrepancy is taken into account when interpreting our data. In terms of ability, the proportion of people with a form of identified disability in the Annandale and Eskdale area, Dumfries and Galloway, and Scotland are 21\%, 22\%, and $19.7 \%$, respectively; these are higher than the $13.9 \%$ of our respondents who identified themselves as having some form of disability. 
These data were first entered into an excel spreadsheet and then transferred to IBM SPSS statistics 24 for analysis. Qualitative text in the comment box (of the semistructured survey) was reviewed to shed further insights into the quantitative data. Qualitative quotes are taken Verbatim. The cross-group analysis was conducted using descriptive statistics and codebooks and identifying mean, median, and mode. Missing values were excluded. We compared means using Kruskal Wallis, nonparametric, and one-way analysis of variance techniques (Siegel and Castellan 1988) to compare across gender, age, and disability. Nonparametric testing does not assume the distribution of data (Pallant 2013) and is useful for this study given the differences in the number of respondents that identified themselves as nondisabled $(n=136)$ and disabled groups $(n=25)$. Therefore, we take care in accepting or making interpretations between disabled and nondisabled groups due to the nature of the data distribution.

\section{Results and Discussion}

The primary data reflect questions around public use of information sources in preparation for and response to the $\mathrm{BfE}$, and the BfE risk communication effectiveness. Our analysis also reflects on the relationship between risk information received and intention to act.

\subsection{Prior Experience of Heavy Snow}

We first sought to understand the respondents' previous experience with the snow event as an "experience," which is identified as a critical factor in shaping risk perception and behavior (Lawrence et al. 2014). Respondents were asked to select all that apply from a list of possible answers.

Our analysis suggests that most of the respondents had experienced previous heavy snowfall disruption in the past. This is expected as cold and heavy snow disruptions are common occurrences in Scotland during winter. Among those with experience, 130 respondents had experienced disruption to daily lives, 22 respondents had experienced damage to property and belongings, 6 respondents had experienced physical and 1 respondent encountered mental health challenges following a substantial snow disruption. The remaining 38 of $180(21 \%)$ respondents in this study indicated that they had no prior experience with heavy snowfall, which may be explained by migration into the region from other warmer regions. The Dumfries and Galloway Health and Social Care Strategic Needs Assessment report (2016-2019) estimates that the net annual average migration into the area is 604 migrants
(Dumfries and Galloway Council Integration Joint Board 2018).

\subsection{Use of Information Sources During the "Beast from the East"}

To determine the use of information sources in the search for risk information during the BfE, we asked respondents where they would go for information about heavy snow if there were a warning alert. Respondents were asked to choose all that applied from a series of potential information sources (Table 2).

Data from the respondents suggest that most of the respondents used public authority sources such as the MET Office $(80.6 \%)$ and Transport Scotland (46.7\%), and online and web sources $(47.2 \%)$. Recent advances in information and communication technologies mean that public authorities use both mainstream (TV, radio) and social media when communicating with the public about disaster risk. Due to critical information communication disruption during and after environmental disasters, however, other studies such as Burger et al. (2013), Steelman et al. (2015), and DeYoung et al. (2016) found that the public relied more on traditional sources and channels of information (TV, radio, friends) in environmental-related emergencies. Other used sources of information are social media $(35.6 \%)$, friends, family, and neighbors (30.6), and emergency services $(22.2 \%)$. The local newspaper $(7.8 \%)$, local councils $(4.4 \%)$, community center $(2.2 \%)$, and members of the community council $(1.1 \%)$ rated lower. There was no distinction made between information "sources" and "channels," and therefore, it should be considered a limitation in this study. The option of mainstream media (such as TV and radio) was not explicit, but some of the respondents noted TV and Radio in the "other" option. Further research should consider making this distinction between information "sources" and "channels" for a more thorough analysis.

One interesting finding is that despite the over-representation of $60+$ years old respondents in this study, online sources for risk information sources were used extensively, suggesting that this age group is increasingly seeking information using the Internet and web sources. This is similar to several studies such as König et al. (2018), van Deursen and Helsper (2015), and Simonova et al. (2020). For example, König et al. (2018), in their study involving over 60,000 Europeans above the age of 50, found a considerable proportion of Internet use among the elderly. Age, as well as prior experience of Internet use, social network, regional context, and social structure were found to be key determinants of the elderly use of the Internet and web sources (Deursen and Helsper 2015). Simonova et al. (2020) also found a relationship between age and Internet 
Table 2 Actual and intended use of information sources

\begin{tabular}{|c|c|c|c|c|}
\hline \multirow[t]{2}{*}{ Information sources } & \multicolumn{2}{|c|}{ No. of actual usage } & \multicolumn{2}{|c|}{ No. of intended usage } \\
\hline & Frequency & Percentage & Frequency & Percentage \\
\hline MET Office & 145 & 80.6 & 121 & 67.2 \\
\hline Online and web & 85 & 47.2 & 101 & 56.1 \\
\hline Transport Scotland & 84 & 46.7 & 76 & 42.2 \\
\hline Social media e.g. Facebook & 64 & 35.6 & 56 & 31.1 \\
\hline Friends, family, and neighbors & 55 & 30.6 & 41 & 22.8 \\
\hline Emergency services e.g. police, fire & 40 & 22.2 & 40 & 22.2 \\
\hline Local newspaper & 14 & 7.8 & 12 & 6.7 \\
\hline Others & 13 & 7.2 & 18 & 10 \\
\hline Local council officials & 8 & 4.4 & 14 & 7.8 \\
\hline Community forum/center & 4 & 2.2 & 5 & 2.8 \\
\hline Member of the community council & 2 & 1.1 & 3 & 1.7 \\
\hline
\end{tabular}

use, with older people using the Internet mostly for socializing, information search, and explorative purposes with additional benefits such as improvement in cognitive flexibility (Mohta and Hadler 2020). Our results suggest that Internet and web sources are increasingly becoming an important source of disaster risk information among the elderly population and should be exploited to communicate about disaster risk to elderly groups, considering its cognitive-improvement benefits.

We found no statistically significant differences in respondents' selection of intended sources of use and actual use of information sources. We distinguish between "intended sources" and "actual use" of information sources as people may want to use specific sources but may be constrained in terms of resources to do so, for example, by lacking either permanent or temporary access to the Internet for social media use. It must be noted that the nature of access or constraint to sources/channels of information will impact on the intention to use that sources/ channels of information. For instance, where there is access constraint to certain channel/source of information, the intention to use that source/channel is likely to be low and vice versa. Our data show a substantial increase in the actual number of respondents who used MET Office and Transport Scotland information sources when compared with the intended usage of the sources. On the other hand, there was a $9 \%$ reduction between intended $(56.1 \%)$ and actual (47.2\%) use of online and web sources. Local newspaper sources moved two ranks upwards from the bottom three when comparing between intended and actual usage of information sources. Steelman et al. (2015) found that the newspaper was the second most used source in their study of five wildfires, with newspapers becoming more prominent as an information source as the disaster prolongs (Quarantelli 2002).

We compared groups across gender, age, and disability using the Kruskal-Wallis nonparametric technique (Pallant 2013) to identify any differences in the use of information sources. If the significance level is less than 0.05 ( $p<$ $0.05)$, a statistically significant difference exists between groups. Our analysis found statistically significant differences in the use of information sources between age and gender and no statistically significant difference in the use of information sources between nondisabled and disabled groups. Further analysis is presented in Table 3.

In terms of gender, there was a statistically significant difference $(p=0.02)$, with male respondents having a higher mean rank value (95.35) when compared to female (83.09) in the use of MET Office sources. Women scored a higher mean rank value for the use of social media (95.19) compared to male groups (87.78), but this was not statistically significant $(p=0.09)$. This finding aligns with the result of Shaw and Gant (2002) and Booker (2018), who noted a slightly higher percentage of female use of social media when compared to males in a developed country context. Future research should consider the extent to which this finding compares to the context of developing countries, where women experience greater difficulty in accessing IT services and have lower IT skills that create conditions for greater reliance on search for information from their local network. Larger sets of data may be needed to ascertain any differences in how males and females use social media in search of disaster risk information.

In terms of age group, we found a statistically significant difference between age groups in their use of emergency services sources (for example, police and fire) and social media. The mean rank rated highly for 41 to 60 -year old, 


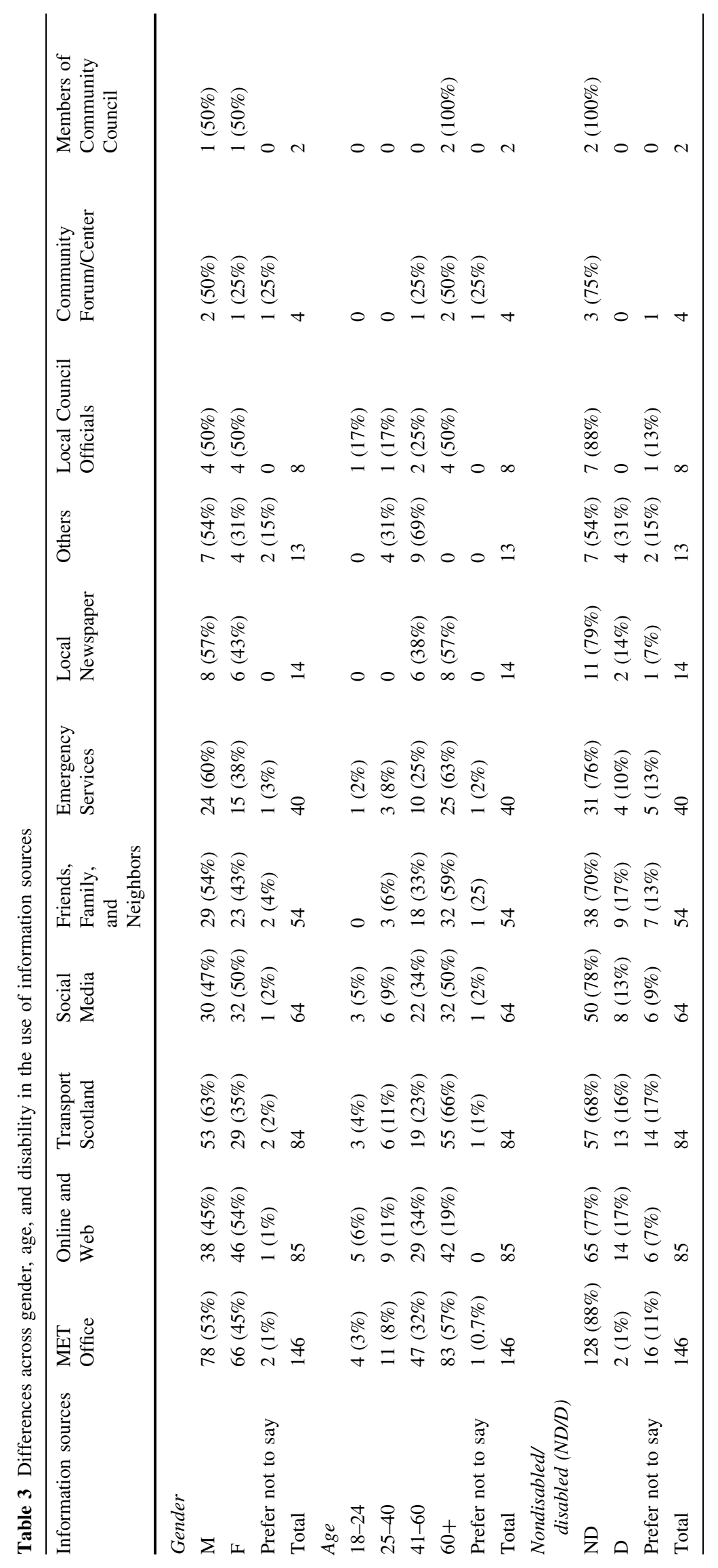


which scored the highest mean rank score of (102.10) in the use of emergency services. Other ratings are 25 to 40 years (99.67), 18 to 24 years (84.83), and $60+$ years (80.79). In terms of the use of social media, 18 to 24 years scored the highest mean rank score of (147.50), followed by 25 to 40 years (117.67), 41 to 60 years (104.95), and $60+$ years scoring the lowest mean score for social media use (74.11). This suggests that social media is a beneficial information source for the younger population. Despite differences in social media use, there were no significant differences between age, gender, and disability in the use of online and web sources.

\subsection{Usefulness, Reliability, and Clarity of Information Received during the "Beast from the East"}

We asked respondents to rate the usefulness, reliability, and clarity of the information received (Table 4). Public authority sources rated highest in terms of usefulness, reliability, and clarity of the risk information communicated with the public regarding heavy snow. Online and web sources, social media, family, friends, and neighbors, and emergency services sources are also rated highly. Family, friends, and neighbors were particularly found to be most useful during the early stages of a disaster but less often as the disaster progressed (Rundblad et al. 2010). Local newspapers and other sources rated highly in terms of clarity only, as the data suggest that these sources are often not relied upon or used in the case of snow emergencies. Local council officials, community centers, and community council members also rated low in terms of usefulness, reliability, and clarity of information.
We further compared the reliability, clarity, and usefulness of the information received across age, gender, and disability. Only one statistically significant difference was found between social media and age in the usefulness of social media sources. Further analysis of social media use and age did not reveal further insight. More research is needed to understand the use of information sources by those living with disabilities in different types of disaster contexts.

\subsection{The Effectiveness of "Beast from the East" Risk Communication and Intention to Act}

To ultimately access public perception of risk communication effectiveness in preparation for and response to the BfE disruption, we identified 10 variables of effective risk communication between authorities and the public-following examples assessed by Breakwell (2000), Covello (2003), Covello et al. (2012), and Williams et al. (2018) among others. These included consistency of messages, simplicity of language used, and the usefulness of the Internet and social media. Other variables are trusted information provider, trust in communication channels, live and regular risk information updates, completeness of the information received, timeliness of information received, two-way communication, and burning questions answered. Respondents were asked to rate the extent to which they agreed with these 10 variables on a scale of 0 to 5. A score of 0 means not applicable, 1 means strongly disagree, and 5 means strongly agree. Eight of the 10 variables scored a median score of 4 , which suggests that risk communication during the BfE to a large extent was deemed effective as respondents agreed that there was the consistency of information shared between the public and

Table 4 Reliability, clarity, and usefulness of risk information received $(0=\mathrm{n} / \mathrm{a}, 1$ lowest score, $5=$ highest score)

\begin{tabular}{llll}
\hline Information sources & $\begin{array}{l}\text { Reliability of Sources } \\
\text { Median }\end{array}$ & $\begin{array}{l}\text { Clarity of Information } \\
\text { Median }\end{array}$ & $\begin{array}{l}\text { Usefulness of Information } \\
\text { Median }\end{array}$ \\
\hline MET Office & 5 & 4 & 4 \\
Online and web & 4 & 4 & 4 \\
Transport Scotland & 4 & 5 & 4 \\
Social media e.g. Facebook & 4 & 4 & 3 \\
Friends, family, and neighbors & 3 & 4 & 3 \\
Emergency services e.g. police, fire & 4 & 4 & 3 \\
Local newspaper & 0 & 4 & 1 \\
Others & 0 & 4 & 1 \\
Local council officials & 0 & 3 & 2 \\
Community forum/center & 0 & 3 & 1 \\
Member of community council & 0 & 2 & 1 \\
\hline
\end{tabular}


Table 5 Advice received during the "Beast from the East" from official sources

\begin{tabular}{lclc}
\hline Advice received & Frequency & Steps taken & Frequency \\
\hline Do not travel & 157 & Did not travel or leave home during the red and amber warning & 116 \\
Things to consider before traveling & 102 & I ensured I had enough fuel in case of supply disruption \\
Keeping warm & 71 & & \\
How to drive safely & 48 & I drove slowly in icy conditions (during and after the red and & 112 \\
& 30 & I identified all potentially useful information sources \\
Information about relevant resources, e.g. & & & \\
$\quad$ emergency number & 15 & I did nothing for other reasons \\
Information about organizations to get help from & 11 & I did nothing because I did not trust the information sources \\
Did not receive any advice & 5 & 1 \\
Other &
\end{tabular}

authorities, the languages used were simple to understand, and Internet and social media sources were useful. Trust in the information provider and communication channel, regular updates from authorities, and timely and complete information rated highly too. The lowest median scores (2) were one-to-one communication with authorities and relevant questions being answered.

We further compared the effectiveness of the risk communication during the BfE across age, gender, and disability. Our analysis shows no statistically significant differences except, again, for age and social media use. Further analysis of age and social media use did not reveal further insight. To shed further insight into the nature of the relationship between risk communication, risk perception, and intention to act, our analysis compared the data on the risk advice received and steps taken as a consequence during the BfE event. Participants were asked to select all responses that applied.

Data in Table 5 suggest that most of the respondents received advice not to travel (157) and information on what to consider before traveling (102) if they must do so; 71 respondents indicated that they had information on keeping warm and a further 48 reviewed how to drive safely in snowy conditions; an additional 30 respondents noted that they received information about relevant emergency resources; 15 participants received information about organizations that offer help; and 11 respondents acknowledged that they had received no prior advice. Our analysis also shows that most of the respondents (116) did not travel during the red and amber warning; 112 of the respondents who travelled during and in the immediate period after the warning period took precautionary measures by driving slowly in icy conditions, and 95 of the respondents bought enough fuel to deal with potential disruptions to fuel supply. Four of the respondents did nothing and one respondent did nothing due to trust issues. This shows that the majority of the respondents in this study adhered to the risk advice received by taking precautionary measures similar to Wachinger et al. (2013) and Yang et al. (2020). Yu et al. (2020) noted that self-efficacy plays an enabling or inhibiting role in adhering to risk advice. Of the respondents, $85 \%$ were very likely or likely to follow future guidance, $7.8 \%$ were somewhat likely, and another $2.3 \%$ were not sure or not likely to follow future advice.

We sought further insight from the qualitative data collected in the semistructured survey to understand potential barriers to the uptake of official advice. Employer's expectations, financial commitment, and work obligations were identified as the key barriers to taking up official risk advice. Quotes in the survey say: "Work obligation means that you must attempt to travel to work unless the road is closed by snow or several feet deep." "[We were] advised not to travel by police/media. Yet employer XXX does not pay staff who can't get to work." "Employer expectations."

A key lesson here is that taking up formal risk advice is not only a function of the effectiveness of the risk communication process per se, but other intervening variables determine if people adhere to official risk advice. This shows a nonlinear relationship between risk communication and intention behave as illustrated in Fig. 1.

\section{Conclusion}

Understanding how to communicate risk and safety information effectively with different public groups is vital to building community resilience to environmental hazards. Therefore, policymakers and resilience practitioners charged with communicating risk must understand the most effective medium to communicate risk to targeted groups and the whole population. Our analysis suggests that the most commonly used source of information for 
heavy snow disaster preparedness were public authority sources such as the MET Office and Transport Scotland. Online and web sources were also highly rated and may be used by public authorities and unofficial sources. Grein et al. (2000) suggested that unofficial sources tend to be the initial source of information providers compared to formal information providers and is especially so where there is an information gap or lack of information from formal authorities. As there is a high reliance on official sources through traditional and web media in environmental hazards and emergencies, as evidenced in this study, timely information from formal sources is crucial to avoid misinformation or fake news from informal sources, which are often the first information provider. An interesting finding in our study is that despite the over-representation of $60+$ years old individuals in our study, online sources as providers of risk information rated highly, suggesting a considerable proportion of Internet use among the elderly.

When we compared across age, gender, and ability groups, our analysis found statistically significant differences in the use of information sources between age and gender, but no statistically significant difference in the use of information sources between non-disabled and disabled groups. Women scored a higher mean rank value for the use of social media than the male groups, similar to other studies such as Shaw and Gant (2002) and Booker (2018). But further studies that draw on a larger data set should substantiate how males and females use social media for disaster risk preparedness. We found that while age was a critical factor in the use of the Internet and social media sources, our study found a good level of use among the elderly population. Younger groups between 18 to 24 and 25 to 40 scored highest in their social media source use, which shows this channel should actively be used in communicating environmental disaster risk when communicating with the younger groups.

The data suggest that there is generally a good understanding among the general public of potential harm from heavy snow and self-confidence in their ability to respond. Knowledge on how to protect self and properties ranked slightly lower. The comparison between disabled and nondisabled groups showed no significant difference in the knowledge and understanding of heavy snow risk. Nevertheless, there is a need for people living with disabilities to be included in resilience planning; hence, encouraging a bottom-up approach to resilience planning is desirable (Wolbring 2009).

Our data also reveal a relationship between risk communication, risk perception, and willingness to mitigate disaster risk, similar to Wachinger et al. (2013). Still, other intervening variables determine if people adhere to official risk advice or not, and this may include the employer's expectations, financial commitments, and work obligations.
We argue that where full adherence to official risk advice is required, politicians and community resilience practitioners should carefully consider work obligations and stakeholder expectations.

Like previous risk communication literature, we conclude that an effective risk communication strategy targeted at the entire population should consider the heterogeneity of the different public groups in society as to how they use information sources to inform their risk perception and disaster preparedness. This is essential to effectively communicate risk with the entire population or public groups deemed to be specifically at-risk. An area for further research is to see how the indicative findings in this study on the information seeking behaviors of individuals in snow disaster preparedness compare with information seeking behaviors in other types of hazards or disaster scenarios and also across communities, countries, or regional context (for example, urban communities, developing countries).

Acknowledgment This research is partly funded by the Scottish Funding Council, as part of the National Centre for Resilince. This research received no external funding.

Open Access This article is licensed under a Creative Commons Attribution 4.0 International License, which permits use, sharing, adaptation, distribution and reproduction in any medium or format, as long as you give appropriate credit to the original author(s) and the source, provide a link to the Creative Commons licence, and indicate if changes were made. The images or other third party material in this article are included in the article's Creative Commons licence, unless indicated otherwise in a credit line to the material. If material is not included in the article's Creative Commons licence and your intended use is not permitted by statutory regulation or exceeds the permitted use, you will need to obtain permission directly from the copyright holder. To view a copy of this licence, visit http://creativecommons. org/licenses/by/4.0/.

\section{References}

Abunyewah, M., T. Gajendran, K. Maund, and S.A. Okyere. 2019. Linking information provision to behavioural intentions. International Journal of Disaster Resilience in the Built Environment 11(1): 100-118.

Adekola, J. 2020. The role of power and expertise in social amplification of risk. In Power and risk in policymaking, ed. J. Adekola, 103-118. Cham: Springer.

Adekola, J., D. Fischbacher-Smith, and M. Fischbacher-Smith. 2019. Light me up: Power and expertise in risk communication and policy-making in the e-cigarette health debates. Journal of Risk Research 22(10): 1294-1308.

Austin, L., B.F. Liu, and Y. Jin. 2012. How audiences seek out crisis information: Exploring the social-mediated crisis communication model. Journal of Applied Communication Research 40(2): 188-207.

Berget, G., A. MacFarlane, and N. Pharo. 2020. Modelling the information seeking and searching behaviour of users with impairments: Are existing models applicable? Journal of Documentation 77(2): 381-400. 
Bronfman, N.C., P.C. Cisternas, P.B. Repetto, and J.V. Castañeda. 2019. Disaster preparedness in a multi-hazard environment: Characterizing the sociodemographic profile of those better (worse) prepared. PloS One 14(4): e0214249.

Booker, C.L., Y.J. Kelly, and A. Sacker. 2018. Gender differences in the associations between age trends of social media interaction and well-being among 10-15 year olds in the UK. BMC Public Health 18(1): 1-12.

Breakwell, G.M. 2000. Risk communication: Fators affecting impact. British Medical Bulletin 56(1): 110-120.

Burger, J., M. Gochfeld, C. Jeitner, T. Pittfield, and M. Donio. 2013. Trusted information sources used during and after Superstorm Sandy: TV and radio were used more often than social media. Journal of Toxicology and Environmental Health, Part A 76(20): $1138-1150$.

Burnside, R., D.S. Miller, and J.D. Rivera. 2007. The impact of information and risk perception on the hurricane evacuation decision-making of greater New Orleans residents. Sociological Spectrum 27(6): 727-740.

Cahyanto, I., L. Pennington-Gray, B. Thapa, S. Srinivasan, J. Villegas, C. Matyas, and S. Kiousis. 2016. Predicting information seeking regarding hurricane evacuation in the destination. Tourism Management 52: 264-275.

CDAC (Communicating with Disaster Affected Communities). 2019. Communicating with communities in the aftermath of Cyclone Idai. http://www.cdacnetwork.org/contentAsset/raw-data/ 426c13e1-d593-4079-8c15-b882b6f4620a/attachedFile. Access 9 May 2021.

Cliff, B.J., L. Morlock, and A.B. Curtis. 2009. Is there an association between risk perception and disaster preparedness in rural US hospitals?. Prehospital and Disaster Medicine 24(6): 512-517.

Crichton Institute. 2014. Dumfries and galloway regional economic strategy: Baseline study and regional economic profile. http:// crichtoninstitute.co.uk/index.php/publications. Accessed 29 Sept 2019.

Covello, V.T. 2003. Best practices in public health risk and crisis communication. Journal of Health Communication 8(S1): 5-8.

Covello, V.T., D.B. McCallum, and M.T. Pavlova, eds. 2012. In Effective risk communication: The role and responsibility of government and nongovernment organizations vol 4, . Cham: Springer.

Cutter, S.L. 2017. The forgotten casualties redux: Women, children, and disaster risk. Global Environmental Change 42: 117-121.

DeYoung, S.E., T. Wachtendorf, A.K. Farmer, and S.C. Penta. 2016. NOAA radios and neighbourhood networks: Demographic factors for channel preference for hurricane evacuation information. Journal of Contingencies and Crisis Management 24(4): $275-285$

Dumfries and Galloway Council. 2020. Report on the current position of poverty and deprivation in Dumfries and Galloway 2020. https://www.dumgal.gov.uk/media/23800/Report-Poverty-andDeprivation-in-Dumfries-and-Galloway-2020/pdf/Poverty-andDeprivation-Position-Report.pdf?m=637424348890330000. Accessed 4 Oct 2020.

Dumfries and Galloway Council Integration Joint Board. 2018. Health and social care strategic needs assessment. https://dghscp. co.uk/wp-content/uploads/2021/05/Strategic-Needs-Assessment. pdf. Accessed 29 Sept 2019.

Fitzpatrick, C., and D.S. Mileti. 1994. Public risk communication. In Disasters, collective behaviour, and social organization, ed. R.R. Dynes, and K.J. Tierney, 71-84. Newark, NJ: University of Delaware Press.

Frewer, L.J., J. Scholderer, and L. Bredahl. 2003. Communicating about the risks and benefits of genetically modified foods: The mediating role of trust. Risk Analysis 23(6): 1117-1133.
Guardian. 2018. Snow disruption continues with roads, railways, hospitals and airports hit-As it happened. https://www.theguar dian.com/uk-news/live/2018/mar/02/uk-weather-snow-disrup tion-storm-emma-beast-from-the-east-live. Accessed 24 Nov 2021.

Grein, T.W., K.B. Kamara, G. Rodier, A.J. Plant, P. Bovier, M.J. Ryan, T. Ohyama, and D.L. Heymann. 2000. Rumors of disease in the global village: Outbreak verification. Emerging Infectious Diseases 6(2): 97-102.

Greening, K., and A. Hodgson. 2019. Atmospheric analysis of the cold late February and early March 2018 over the UK. Weather 74(3): 79-85.

Griffin, R.J., K. Neuwirth, S. Dunwoody, and J. Giese. 2004. Information sufficiency and risk communication. Media Psychology 6(1): 23-61.

Hansson, S., K. Orru, A. Siibak, A. Bäck, M. Krüger, F. Gabel, and C. Morsut. 2020. Communication-related vulnerability to disasters: A heuristic framework. International Journal of Disaster Risk Reduction 51: Article 101931.

Hill, C., and D. Clelland. 2015. Poverty and deprivation in the Dumfries and Galloway: A spatial approach. http://eprints.gla.ac. uk/108111/1/108111.pdf. Accessed 9 Nov 2019.

Huber, D.G., and J. Gulledge. 2011. Extreme weather and climate change: Understanding the link, managing the risk. Arlington, VA: Center for Climate and Energy Solutions (C2ES).

Hoffmann, R., and R. Muttarak. 2017. Learn from the past, prepare for the future: Impacts of education and experience on disaster preparedness in the Philippines and Thailand. World Development 96: 32-51.

Holmes, B., N. Henrich, S. Hancock, and V. Lestou. 2009. Communicating with the public during health crises: Experts' experiences and opinions. Journal of Risk Research 12(6): 793-807.

IOM (International Organization for Migration). 2014. Communicating with communities. A case study and guide from Pakistan and elsewhere. https://reliefweb.int/sites/reliefweb.int/files/ resources/Communicating_with_Communities_A_Case_Study_ and_Guide_from_Pakistan_and_Elsewhere.pdf. Accessed 9 May 2021.

Jin, Y., B.F. Liu, and L.L. Austin. 2014. Examining the role of social media in effective crisis management: The effects of crisis origin, information form, and source on publics' crisis responses. Communication Research 41(1): 74-94.

Kasperson, J.X., and R.E. Kasperson. 2012. Social contours of risk: Volume-I: Publics, risk Communication and the social. London: Routledge.

Kasperson, R.E., O. Renn, P. Slovic, H.S. Brown, J. Emel, R. Goble, J.X. Kasperson, and S. Ratick. 1988. The social amplification of risk: A conceptual framework. Risk Analysis 8(2): 177-187.

König, R., A. Seifert, and M. Doh. 2018. Internet use among older Europeans: An analysis based on SHARE data. Universal Access in the Information Society 17(3): 621-633.

Lawrence, J., D. Quade, and J. Becker. 2014. Integrating the effects of flood experience on risk perception with responses to changing climate risk. Natural Hazards 74(3): 1773-1794.

Lindell, M.K., and R.W. Perry. 2012. The protective action decision model: Theoretical modifications and additional evidence. Risk Analysis 32(4): 616-632.

Madhuri, H.R. Tewari., and P.K. Bhowmick. 2015. Ingenuity of skating on marshy land by tying a pot to the belly: Living with flood is a way of life. Environment Development and Sustainability 17(6): 1287-1311.

Mayhorn, C.B. 2005. Cognitive aging and the processing of hazard information and disaster warnings. Natural Hazards Review 6(4): $165-170$. 
Met Office. 2018. Weather warnings guide. https://www.metoffice. gov.uk/guide/weather/warnings. Accessed 9 Nov 2019.

Miceli, R., I. Sotgiu, and M. Settanni. 2008. Disaster preparedness and perception of flood risk: A study in an alpine valley in Italy. Journal of Environmental Psychology 28(2): 164-173.

Mohta, R., and S. Halder. 2020. An exploratory study of internet use pattern, cognitive flexibility and quality of life in elderly population. Indian Journal of Gerontology 34(4): 413-427.

Pallant, J. 2013. SPSS survival manual: A step by step guide to data analysis using IBM SPSS, 4th edn. Crows Nest, NSW: Allen \& Unwin.

Palttala, P., C. Boano, R. Lund, and M. Vos. 2012. Communication gaps in disaster management: Perceptions by experts from governmental and non-governmental organizations. Journal of Contingencies and Crisis Management 20(1): 2-12.

Paton, D., L. Smith, and D. Johnston. 2005. When good intentions turn bad: Promoting natural hazard preparedness. The Australian Journal of Emergency Management 20(1): 25-30.

Paul, B.K., and R.H. Bhuiyan. 2010. Urban earthquake hazard: Perceived seismic risk and preparedness in Dhaka City, Bangladesh. Disasters 34(2): 337-359.

Quarantelli, E.L. 2002. The role of the mass communication system in natural and technological disasters and possible extrapolation to terrorism situations. Risk Management 4(4): 7-21.

Rakib, M., S. Islam, I. Nikolaos, M. Bodrud-Doza, and M.A. Bhuiyan. 2017. Flood vulnerability, local perception and gender role judgment using multivariate analysis: A problem-based "participatory action to Future Skill Management" to cope with flood impacts. Weather and Climate Extremes 18: 29-43.

Rundblad, G., O. Knapton, and P.R. Hunter. 2010. Communication, perception and behaviour during a natural disaster involving a "Do Not Drink" and a subsequent "Boil Water" notice: A postal questionnaire study. BMC Public Health 10(1): 1-12.

Ryan, B. 2013. Information seeking in a flood. Disaster Prevention and Management: An International Journal 22(3): 229-242.

Ryan, B. 2018. A model to explain information-seeking behaviour by individuals in the response phase of a disaster. Library \&amp; Information Science Research 40(2): 73-85.

Shannon, C.E., and W. Weaver. 1949. The mathematical theory of communication. Urbana, IL: The University of Illinois Press.

Shaw, L.H., and L.M. Gant. 2002. In defence of the Internet: The relationship between Internet communication and depression, loneliness, self-esteem, and perceived social support. Cyberpsychology \&amp; Behaviour 5(2): 157-171.

Siegel, S., and N. Castellan. 1988. Nonparametric statistics for the behavioural sciences, 2nd edn. New York: McGraw-Hill.
Simonova, I., P. Poulova, P. Prazak, and B. Klimova. 2020. Older adults as the internet users: Age and gender approach. International Journal of Innovation and Learning 27(4): 467-482.

Slovic, P. 2010. The feeling of risk: New perspectives on risk perception. London: Routledge.

Slovic, P., M.L. Finucane, E. Peters, and D.G. MacGregor. 2004. Risk as analysis and risk as feelings: Some thoughts about affect, reason, risk, and rationality. Risk Analysis 24(2): 311-322.

Sommerfeldt, E.J. 2015. Disasters and information source repertoires: Information seeking and information sufficiency in postearthquake Haiti. Journal of Applied Communication Research 43(1): $1-22$.

Spence, P.R., J. McIntyre, K.A. Lachlan, M.E. Savage, and M.W Seeger. 2011. Serving the public interest in a crisis: Does local radio meet the public interest?. Journal of Contingencies and Crisis Management 19(4): 227-232.

Steelman, T.A., S.M. McCaffrey, A.-L.K. Velez, and J.A. Briefel. 2015. What information do people use, trust, and find useful during a disaster? Evidence from five large wildfires. Natural Hazards 76(1): 615-634.

Sutton, J.N., L. Palen, and I. Shklovski. 2008. Backchannels on the front lines: Emergency uses of social media in the 2007 Southern California Wildfires. Denver, CO: University of Colorado.

Tversky, A., and D. Kahneman. 1974. Judgment under uncertainty: Heuristics and biases. Science 185(4157): 1124-1131.

van Deursen, A.J.A.M., and E.J. Helsper. 2015. A nuanced understanding of Internet use and non-use among the elderly. European Journal of Communication 30(2): 171-187.

Wachinger, G., O. Renn, C. Begg, and C. Kuhlicke. 2013. The risk perception paradox-Implications for governance and communication of natural hazards. Risk Analysis 33(6): 1049-1065.

Williams, B.D., J.N. Valero, and K. Kim. 2018. Social media, trust, and disaster: Does trust in public and nonprofit organizations explain social media use during a disaster?. Quality \&amp; Quantity 52(2): 537-550.

Wolbring, G. 2009. A culture of neglect: Climate discourse and disabled people. M/C Journal 12(4). https://doi.org/10.5204/mcj. 173

Yang, F., J. Tan, and L. Peng. 2020. The effect of risk perception on the intention to purchase hazard insurance-A case study in the Three Gorges Reservoir region, China. International Journal of Disaster Risk Reduction 45: Article 101379.

Yu, J., T. Sim, W. Qi, and Z. Zhu. 2020. Communication with local officials, self-efficacy, and individual disaster preparedness: A case study of rural northwestern China. Sustainability 12(13): Article 5354. 